\title{
Las amenazas y oportunidades del consumidor en la contratación electrónica en España
}

\section{The Threats and Opportunities of the Consumer in Electronic Contracting in Spain}

María Cristina Cintora Egea*: http://orcid.org/0000-0001-5507-8444

http://dx.doi.org/10.21503/lex.v19i27.2253

* Profesora asociada de Derecho Civil de la Universidad de Extremadura y abogada en ejercicio. España

Correo electrónico: mcintora@unex.es

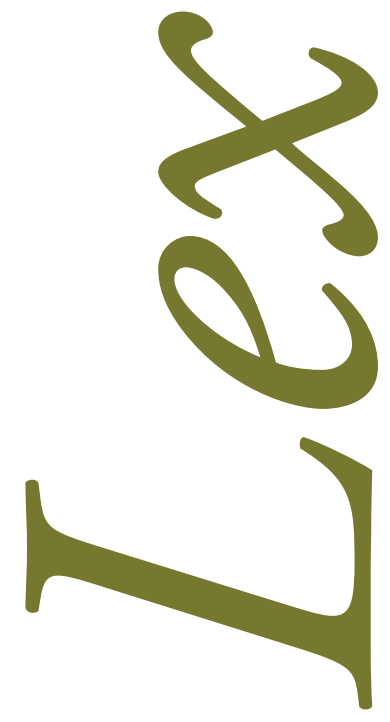




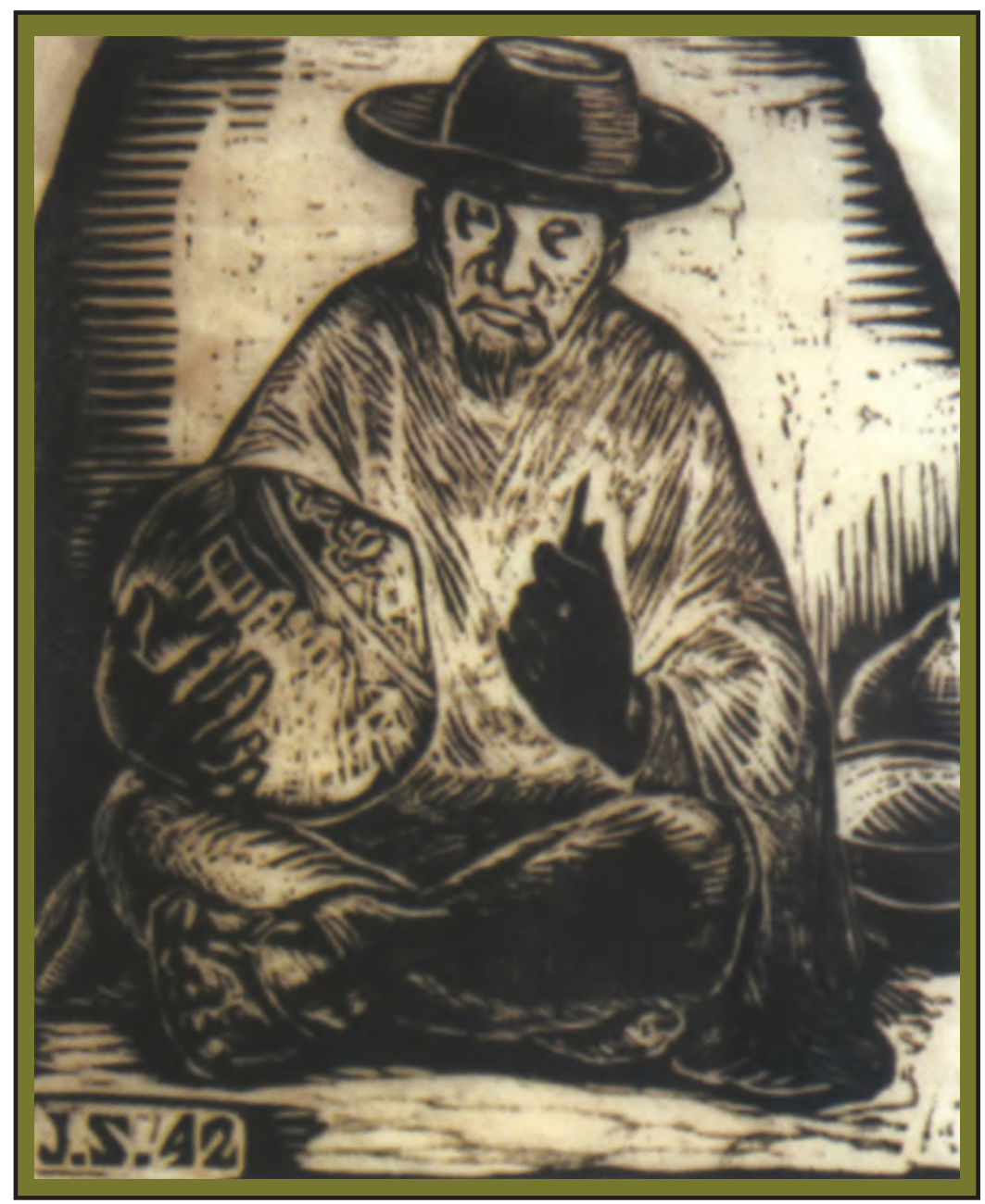

Burilador de mates. José Sabogal pintor peruano del indigenismo (Cajabamba-Cajamarca, 1888-1957). 


\section{RESUMEN}

En el presente trabajo se realizará una aproximación a la figura del consumidor en la contratación electrónica, los derechos y mecanismos que cuenta el consumidor para el ejercicio de sus derechos, así como los canales a través de los cuales se pueden hacer efectivos.

Palabras clave: Consumidor, empresario, contratación electrónica, desistimiento.

\section{ABSTRACT}

In the present work an approach will be made to the figure of the consumer in electronic contracting, the rights and mechanisms that the consumer has to exercise their rights as well as the channels through which they can be made effective.

Key words: Consumer, entrepreneur, electronic contracting, withdrawal. 


\section{INTRODUCCIÓN}

En determinadas épocas del año, como por ejemplo en las celebraciones navideñas, llegan las compras, a veces compulsivas, animadas no solo por el espíritu de la Navidad sino por fenómenos como el Black Friday o el Cyber Monday que hacen que el comercio electrónico, o lo que es lo mismo las compras online, se disparen.

Y es que hoy día algo más de la mitad de los contratos que se celebran son electrónicos, es decir son contratos en los que se utilizan dispositivos electrónicos, motivados en gran medida por la comodidad que supone al consumidor adquirir un producto sin tener que moverse de casa.

Pese a ello y al aumento o crecimiento constante de esta forma de contratar, es muy habitual que el consumidor desconozca los derechos y deberes que se aplican a la hora de celebrar estos contratos. Es así que esta "revolución del contrato electrónico" hizo necesario que el legislador se pusiera a trabajar para dotar de cobertura legal a estas prácticas comerciales y dotar al consumidor de mecanismos de protección en sus relaciones con los empresarios.

\section{APROXIMACIÓN A LA FIGURA DE CONSUMIDOR Y EMPRESARIO}

Desde un punto de vista jurídico existen numerosas definiciones del término consumidor, coincidiendo todas en que se trata de aquella persona física o jurídica que adquiere a título oneroso bienes o servicios para su consumo o beneficio particular ${ }^{1}$.

De ahí que la idea principal entorno al concepto de consumidor sea que esa persona física o jurídica no actúa como empresario en esa relación contractual. Así se pone de manifiesto en el artículo 2 de la Directiva 98/6/CE del Parlamento Europeo y del Consejo, de 16 de febrero de 1998, relativa a la protección de los consumidores en materia de indicación de los precios de los productos ofrecidos a los consumidores en cuyo apartado e) define la figura del consumidor como $<<$ cualquier persona física que compre un producto con fines ajenos a su actividad comercial o profesional $>>$. En idénticos términos se pronuncia la Directiva 2005/6/CE relativa a las prácticas comerciales desleales de las empresas en sus relaciones con los

1. Ghunter Flass, "El concepto de consumidor", Anuario de Derecho Civil, 12 (2017): 21. 
consumidores en el mercado interior, en su artículo 2 apto. a) cuando expresa que se trata de $<<$ cualquier persona física que, en las prácticas comerciales contempladas por la presente Directiva, actúe con un propósito ajeno a su actividad económica, negocio, oficio o profesión>>.

Por lo que se observa la definición de consumidor está en clara contraposición con el término comerciante, definido por esa misma Directiva 2005/6/CE como <<cualquier persona física o jurídica que, en las prácticas comerciales contempladas por la presente Directiva, actúe con un propósito relacionado con su actividad económica, negocio, oficio o profesión, así como cualquiera que actúe en nombre del comerciante o por cuenta de éste>>.

Estas definiciones han sido incorporadas a nuestro ordenamiento jurídico y así las encontramos en los artículos 3 y 4 del Real Decreto Legislativo 1/2007 de 16 de noviembre por el que se aprueba el Texto refundido de la Ley General para la Defensa de los Consumidores y Usuarios y otras leyes complementarias.

De esta forma las dos partes que intervienen en las relaciones de consumo van a ser de un lado el consumidor y de otro el comerciante o empresario siendo la nota distintiva fundamental que el primero será el destinatario final del producto, al adquirirlo para su propio consumo mientras que en el caso de los comerciantes o empresarios, serán aquellos que sin constituirse en destinatarios finales, adquieran, almacenen, utilicen o consuman bienes o servicios, con el fin de integrarlos en procesos de producción, transformación, comercialización o prestación a terceros ${ }^{2}$.

\section{COMERCIO ELECTRÓNICO Y CONTRATACIÓN ELECTRÓNICA}

Una vez establecido el concepto de consumidor y empresario, tenemos que pasar a distinguir las figuras de comercio electrónico y contratación electrónica, términos que se emplean de forma indistinta para referirse a lo mismo, pero que como veremos a continuación tienen sus connotaciones propias y distintivas.

\section{A) Distinción entre ambas figuras}

No existe, en realidad, una definición propiamente dicha del término comercio electrónico, al menos en cuanto a textos legislativos se refiere, si bien podemos extraer algunas de algunos textos de órganos internacionales y sobre todo doctrinales, de diversos autores que se han encargado de hacer un estudio sobre la materia.

La Organización Mundial del Comercio (OMC) se refirió al concepto de comercio electrónico como la producción, distribución, comercialización, venta o entrega de bienes y servicios por medios electrónicos ${ }^{3}$.

2. Manuel Jesús Marín López, "El "nuevo" concepto de consumidor y empresario tras la Ley 3/2014, de reforma del TRLGDCU”, Revista CESCO de Derecho de Consumo, 9 (2014): 12. http://www.revista.uclm.es/index.php/cesco

3. Definición extraída del apartado 1.3 del Programa de Trabajo sobre Comercio electrónico adoptado por el Consejo General de la OMC el 25 de septiembre de 1998. 
Por su parte la Comisión Europea definió el comercio electrónico refiriéndose a todo intercambio de datos por medios electrónicos, esté relacionado o no con la actividad comercial en sentido estricto ${ }^{4}$.

Como puede apreciarse ambas definiciones parten de la idea genérica de "comercio" entendida como la actividad cuyo objeto y finalidad es el intercambio de bienes y servicios, con la única particularidad que será electrónico si para la realización de dichas actividades se utilizan mecanismos electrónicos como Internet.

En esta misma línea se sitúa la doctrina más relevante en la materia, así Mateu de Ros concibe el comercio electrónico como la oferta y contratación electrónica de productos y servicios a través de dos o más ordenadores o terminales informáticos conectados a través de una línea de comunicación dentro del entorno de red abierta que constituye Internet ${ }^{5}$.

El término de contratación electrónica, en cambio, lo encontramos definido en nuestra Ley 34/2002 de 11 de julio de Servicios de la Sociedad de la información y de comercio electrónico (LSSI), que nos indica que se trata de todo contrato en el que la oferta y la aceptación se transmiten por medio de equipos electrónicos de tratamiento y almacenamiento de datos, conectados a una red de telecomunicaciones ${ }^{6}$.

De ahí que podamos decir que la contratación electrónica, o mejor dicho contrato electrónico será aquel contrato en el que se emplee algún medio electrónico, debiendo contar como todo contratos con los requisitos imprescindibles para su validez y eficacia, esto es consentimiento, objeto y causa ${ }^{7}$. Por ello podemos decir que es un supuesto más de contratación a distancia, puesto que no existe un contacto presencial entre los sujetos sino que el contacto entre ellos se lleva a cabo a través de medios informáticos ${ }^{8}$.

4. Comunicación de la Comisión Europea al Consejo, al Parlamento Europeo y al Comité Económico y Social Europeo sobre la aplicación de la Directiva 200/31/CE relativa a determinados aspectos jurídicos de los servicios de la sociedad de la información, en particular el comercio electrónico en el mercado interior, COM, № 702, Bruselas, 2003.

5. Rafael Mateu de Ros, "El consentimiento y el proceso de contratación electrónica”, en Derecho de Internet, contratación electrónica y firma digital, ed. Por Rafael Mateu de Ros y Juan Manuel Cendoya Méndez de Vigo (Pamplona, Aranzadi, 2000).

6. Ley 34/2002, de 11 de julio, de servicios de la sociedad de la información y de comercio electrónico, BOE núm. 166, de 12/07/2002: Anexo. Definiciones. A los efectos de efectos de la presente Ley se entenderá por: e) «Contrato celebrado por vía electrónica» o "contrato electrónico»: todo contrato en el que la oferta y la aceptación se transmiten por medio de equipos electrónicos de tratamiento y almacenamiento de datos, conectados a una red de telecomunicaciones.

7. Real Decreto de 24 de julio de 1889 por el que se publica el Código Civil, «Gaceta de Madrid» núm. 206, de 25/07/1889. Artículo 1262: No hay contrato sino cuando concurren los requisitos siguientes: $1^{\circ}$ Consentimiento de los contratantes. $2^{\circ}$ Objeto cierto que sea materia del contrato. $3^{\circ}$ Causa de la obligación que se establezca.

8. Alejandro Platero Alcón y Cristina Jiménez Asensio, "El consumidor online en el ordenamiento jurídico español", Revista Nuevo Derecho, 21 (2017): 59. 
La doctrina autorizada considera que el contrato electrónico es $<<$ todo acto de compra-venta realizado por Internet, pero también lo es la contratación de servicios o incluso la aceptación de una política de privacidad, las condiciones de uso de una red social, siempre que se haga igualmente a través de la $\operatorname{Red}^{9}>>$.

De esta forma el contrato electrónico presentará una serie de características:

a) En ellos se emplean mecanismos electrónicos.

b) La oferta y la aceptación del contrato se realizará por esos medios electrónicos.

c) Los equipos empleados para contratar admitirán el tratamiento y almacenamiento de datos.

d) La contratación se realizará a distancia.

Son esas peculiaridades propias las que le distinguen de la contratación a distancia y hacen que la regulación de esta figura en la Ley General de Defensa de Consumidores y Usuarios (LGDCU) venga recogida en preceptos distintos, en concreto en el artículo 94 de dicho cuerpo normativo ${ }^{10}$.

B) Normativa aplicable a la contratación electrónica.

Teniendo en cuanta las características del contrato electrónico donde, "tanto la negociación c la conclusión de la contratación y el pago se efectúan electrónicamente, manifestándose el consentimiento a través del teclado, debiendo el consumidor adherir a extensas condiciones generales (términos y condiciones), lo cual hace aplicable al caso el fenómeno regulador de los contratos de adhesión ya que todo el sistema responde al criterio de organización del proveedor a través de su sitio web" ${ }^{11}$, se hace necesario delimitar claramente, la normativa que puede resultarle de aplicación. Así, la misma será:

Las disposiciones sobre obligaciones y contratos del Código Civil (CC) con sujeción a los principios de libertad y autonomía de la voluntad.

Las normas preceptivas del Código de Comercio cuando la contratación es entre comerciantes.

Las disposiciones del Real Decreto Legislativo 1/2007 de 16 de noviembre por el que se aprueba el Texto refundido de la Ley general para la defensa de los Consumidores y usuarios y otras leyes complementarias $(L G D C U)$ que contiene un marco normativo protector de esta clase de receptores de bienes o servi-

9. Rodrigo Bercovitz Rodríguez-Cano, Tratados de contratos. Tomo II, (Valencia: Tirant Lo Blanch, Valencia, 2013 ): 32. 10. Artículo 94 del Real Decreto legislativo 1/2007 de 16 de noviembre por el que se aprueba el Texto refundido de la Ley General de Defensa de los Consumidores y Usuarios, sobre Comunicaciones comerciales y contratación electrónica, «BOE» núm. 287, de 30/11/2007.

11. Carlos Eduardo Tambussi, "Decisiones judiciales referidas al comercio electrónico en la Argentina desde el derecho de consumidores y usuarios", en Lex Revista de la Facultad de Derecho y Ciencia Política de la Universidad Alas Peruanas, 16, 22 (2018): 105. 
cios, cuyas normas de obligado cumplimiento se destinan a la información del consumidor, redacción de las cláusulas en el contrato, régimen de garantías y responsabilidades y determinación de cláusulas abusivas.

Ley 34/2002 de 11 de julio de Servicios de la Sociedad de la información y de comercio electrónico (LSSI).

La Ley 7/1998 de 14 de abril sobre las cláusulas predispuestas en los contratos de adhesión, al ser ésta la forma de contratación más común en internet.

La Ley 7/1996 de 15 de enero de Comercio Minorista, en la que se regula la venta a distancia.

La Ley 7/1998 de 13 de abril de Condiciones Generales de contratación.

El Real Decreto Ley 14/1999 de 17 de septiembre sobre la firma electrónica.

El Real Decreto 1906/1999 de 17 de diciembre que regula la contratación telefónica o electrónica con condiciones generales en desarrollo del art. 5.3 de la Ley 7/1998 de 13 de abril, de condiciones generales de la contratación.

La Ley Modelo de la Comisión de Naciones Unidas para el derecho Mercantil Internacional sobre Comercio Electrónico.

La Directiva 93/13/CE, de 5 de abril de 1993 sobre cláusulas abusivas en Contratos celebrados con consumidores.

La Directiva 97/7, de 20 de mayo, de Protección de los Consumidores en Materia de Contratos a Distancia.

La Directiva 99/93 de 13 de diciembre, por la que se establece un Marco Comunitario para la Firma Electrónica.

La Directiva 2000/31/CE de 8 de junio, de aspectos jurídicos de los Servicios de la Información, en particular el Comercio Electrónico en el Mercado Interior.

\section{DERECHOS DEL CONSUMIDOR EN LA CONTRATACIÓN ELECTRÓNICA}

En la contratación electrónica al no existir un contacto personal o entre los sujetos se hace necesario más que nunca garantizar el derecho de información del consumidor, antes, durante y después de celebrarse el contrato ${ }^{12}$.

12. Juan, Picatoste Bobillo, "El derecho de información en la contratación con consumidores", Actualidad Civil, 4 (2011): 12 . 
El deber de información en este tipo de contratos viene recogido en dos textos legales, en concreto en los artículos 60 a 97 de la LGDCU y en los artículos 10, 27 y 28 de la LSSI.

Partiendo de esos textos legales hay que hablar de un deber general de información que debe prestar el empresario, información que ha de prestarse de manera permanente y gratuita al consumidor y que irá referida a:

1. El nombre y razón social del empresario.

2. Datos completos de contacto (domicilio, debiendo indicarse la dirección de un establecimiento permanente en España, en todo caso cuando el empresario no sea español; correo electrónico.

3. Datos del comerciante por cuya cuenta actúe quien realice la oferta.

4. Datos de inscripción registral.

5. Datos sobre autorizaciones administrativas que se requieran por la actividad que se desarrolle.

6. Datos de identificación fiscal: DNI (persona física) o CIF (persona jurídica) según corresponda.

7. Códigos de conducta que le sean aplicables.

8. Datos de actividades reguladas, como número de colegiado.

$\mathrm{Al}$ margen de esta información de carácter general, el empresario deberá ofrecer al consumidor determinada información antes de la formalización del contrato. Esta información ha de llevarse a cabo por escrito, de forma permanente, sencilla y gratuita para el consumidor, siguiendo los dictados del art. 97 de la LGDCU, artículo 40 de la Ley del Comercio Minorista y del art. 27 de la LSSI.

Esta información previa al contrato irá referida a los siguientes extremos:

1. Información acerca de si el prestador (empresario) va a archivar el documento del contrato y cuál es la accesibilidad al mismo.

2. Información sobre los medios técnicos de que vaya a disponer el consumidor para identificación y corrección de errores en la introducción de datos.

3. Información sobre el bien o servicio concreto que se presta, tales como características del mismo, fecha y forma de entrega, duración que tiene el contrato, si se trata de un contrato de ejecución permanente o repetida.

4. Información sobre el proceso de compra, tales como pasos a seguir, sistema de pago, plazos de entrega, transporte de los bienes, selección de productos etc. 
5. Información sobre el importe, indicando el plazo que tiene la oferta emitida, si el importe incluye o no impuestos y cuál es la cobertura de los gastos de envío.

6. Información sobre las garantías, derechos y servicios postventa: Información sobre el derecho de desistimiento, en qué plazo y cómo ejercerlo, o si por el contrario el consumidor no tiene ese derecho; información acerca de si el empresario está sujeto a algún procedimiento extrajudicial de solución de conflictos; poner a disposición del consumidor las condiciones generales en caso de tratarse de un contrato sujeto a las mismas.

Una vez perfeccionado el contrato, establece el art. 99.2 de la LGDCU que el empresario entregará una copia del contrato firmado o de la confirmación del mismo en papel o en soporte duradero diferente, permitiendo así contar con esa información en cualquier momento futuro de ser necesario.

\section{EL DERECHO DE DESISTIMIENTO EN LA CONTRATACIÓN ELECTRÓNICA}

\section{A. Concepto y Regulación}

El derecho de desistimiento no es otra cosa que $<<$ la facultad del consu $\neg$ midor y usuario de dejar sin efecto el contrato celebrado, notificándoselo así a la otra parte contratante en el plazo establecido para el ejercicio de ese derecho, sin necesidad de justificar su decisión y sin penalización de ninguna clase ${ }^{13}>>$. Este derecho en la contratación electrónica tiene su razón de ser en la posibilidad del consumidor de ver y probar el producto que adquiere, comprobando así si se ajusta a las necesidades y utilidades para las que el consumidor lo compra ${ }^{14}$ ya que no existe un contacto personal con el vendedor y el establecimiento.

El Common Frame of referente (CFR) o Marco Común de Referencia para el Derecho Privado Europeo recoge este derecho en su capítulo V dentro del libro II, poniendo de manifiesto que se trata de un derecho que puede ejercerse en todo contrato celebrado con consumidores ${ }^{15}$.

13. Ignacio Beluche Rincón, El derecho de desistimiento del consumidor, (Valencia: Tirant lo Blanch, Valencia, 2009$): 45$. 14. Considerando 37 de la Directiva 2011/83/CE: Dado que en las ventas a distancia el consumidor no puede ver los bienes antes de celebrar el contrato, debe disponer de un derecho de desistimiento. Por el mismo motivo, el consumidor debe estar autorizado a probar e inspeccionar los bienes que ha comprado en la medida suficiente que le permita determinar la naturaleza, las características y el buen funcionamiento de los bienes En cuanto a los contratos celebrados fuera del establecimiento, debe permitirse al consumidor que ejerza un derecho de desistimiento, ya que puede haber un elemento sorpresa o presión psicológica. El ejercicio del derecho de desistimiento debe poner fin a la obligación de las partes contratantes de ejecutar el contrato.

15. "Cuando las facultades de desistimiento no se limitan a aquellos casos en que el consumidor es cogido desprevenidamente o contrata de forma impersonal, hay que preguntarse cuál es la razón para concederlas, y hasta qué punto no será ya entonces lógico conceder ese derecho al consumidor en cualquier contrato que celebre”. 
La normativa Europea ya recogía este derecho ${ }^{16}$, así aparece en la Directiva 97/7/CE sobre protección de los consumidores en la contratación a distancia, en esta norma se reconocía el ejercicio de este derecho en el plazo de 7 días ${ }^{17}$, la Directiva 2008/48/CE sobre los contratos de crédito al consumo también se refiere al derecho de desistimiento que podrá ejercer el consumidor en el plazo de 14 días en este caso ${ }^{18}$, y la Directiva 2011/83/CE sobre derechos de los consumidores ${ }^{19}$.

En nuestro Ordenamiento jurídico el artículo 10 de la Ley 7/1996 de 15 de enero de Ordenación del Comercio Minorista modificada después por la Ley 47/2002 de 19 de diciembre como consecuencia de la transposición a nuestro ordenamiento de la Directiva 97/7/CE, ya reconocía este derecho ${ }^{20}$.

Otras leyes sectoriales también lo incluyeron en su articulado como la Ley 28/1998 de 13 de julio sobre venta a plazo de bienes muebles, ${ }^{21}$ y la Ley 4/2012 de 6 de julio de contrato de aprovechamiento por turnos de bienes de uso turístico de adquisición de productos vacacionales de larga duración, de reventa y de intercambio y normas tributarias. ${ }^{22}$

En materia de consumo este derecho viene recogido en el RDL 1/2007 de 16 de noviembre por el que se aprueba el texto refundido de la Ley General para la Defensa de los Consumidores y Usuarios y otras leyes complementarias ${ }^{23}$, en su doble vertiente, es decir para los contratos en general ${ }^{24}$ y para los

16. Ángel Acedo Penco, "Fundamentos constitucionales de la protección jurídica de los consumidores en el ordenamiento español y en la Unión Europea”, Ius: revista del Instituto de Ciencias Jurídicas de Puebla, 29 (2012):10.

17. Art. 6.1: 1 . Respecto a todo contrato negociado a distancia, el consumidor dispondrá de un plazo mínimo de siete días laborables para rescindir el contrato sin penalización alguna y sin indicación de los motivos. El único gasto que podría imputarse al consumidor es el coste directo de la devolución de las mercancías al proveedor.

18. Artículo 14. "El consumidor dispondrá de un plazo de 14 días civiles para desistir del contrato de crédito sin indicar el motivo".

19. Artículo 9. "Salvo en caso de aplicación de las excepciones establecidas en el artículo 16, el consumidor dispondrá de un período de 14 días para desistir de un contrato a distancia o celebrado fuera del establecimiento, sin indicar el motivo y sin incurrir en ningún coste distinto de los previstos en el artículo 13, apartado 2, y en el artículo 14".

20. Redacción actual del artículo 10 de la Ley 7/1996 de 15 de Enero: "Para el ejercicio del derecho de desistimiento se estará a lo dispuesto por el artículo 71 del texto refundido de la Ley General para la Defensa de los Consumidores y Usuarios y otras leyes complementarias, aprobado mediante Real Decreto Legislativo 1/2007, de 16 de noviembre".

21. Artículo 9 de la Ley 28/1998, de 13 de julio, de Venta a Plazos de Bienes Muebles, «BOE» núm. 167, de 14 de julio de 1998 .

22. Artículo 12 de la Ley 4/2012, de 6 de julio, de contratos de aprovechamiento por turno de bienes de uso turístico, de adquisición de productos vacacionales de larga duración, de reventa y de intercambio y normas tributarias, «BOE» núm. 162, de 07/07/2012.

23. Un exhaustivo análisis de su texto puede encontrarse en la obra de Ángel Acedo Penco, Derecho de consumo: análisis jurídico-privado de la Ley General para la Defensa de los Consumidores de 2007, (Madrid: Dykinson, 2012).

24. Artículo 68.1: Contenido y régimen del derecho de desistimiento: 1. El derecho de desistimiento de un contrato es la facultad del consumidor y usuario de dejar sin efecto el contrato celebrado, notificándoselo así a la otra parte contratante en el plazo establecido para el ejercicio de ese derecho, sin necesidad de justificar su decisión y sin penalización de ninguna clase. Serán nulas de pleno de derecho las cláusulas que impongan al consumidor y usuario una penalización por el ejercicio de su derecho de desistimiento. 
contratos celebrados a distancia ${ }^{25}$ marco en el cual se desarrolla la contratación electrónica.

\section{B. Plazo para ejercer el derecho de desistimiento en la contratación electrónica}

El plazo de que dispone el consumidor para ejercer el desistimiento en la contratación electrónica, o mejor dicho en los contratos a distancia o fuera del establecimiento mercantil coincide con el plazo del régimen general del desistimiento, esto es el consumidor podrá desistir del contrato en el plazo de 14 días naturales desde que recibe el producto o desde la celebración del contrato cuando estemos en prestaciones de servicios. ${ }^{26}$

No obstante lo anterior, prevé la norma que en el supuesto de que el empresario incumpla con los deberes de información del artículo 97.1 letra i (no informa del derecho de desistimiento, sus condiciones, su plazo, los procedimientos y el modelo de formulario de desistimiento), el plazo de desistimiento empezaría en el momento en que termine el período de desistimiento inicial de 14 días y se extendería 12 meses más ${ }^{27}$. Si el empresario proporciona al consumidor la debida información sobre este derecho dentro de los 12 meses desde la entrega del producto al consumidor o desde la celebración del contrato, el plazo para desistir será de 14 naturales desde que el empresario ofreció la mencionada información.

\section{Requisitos para ejercer el derecho de desistimiento.}

Como hemos indicado en la contratación a distancia, el empresario sigue estando obligado a ofrecer información al consumidor sobre el derecho de desistimiento, tal como estipula el art. 97.1 letras i y j

25. Artículo 102 Derecho de desistimiento: 1. Salvo las excepciones previstas en el artículo 103, el consumidor y usuario tendrá derecho a desistir del contrato durante un periodo de 14 días naturales sin indicar el motivo y sin incurrir en ningún coste distinto de los previstos en los artículos 107.2 y 108.

26. Artículo 104. Plazo para el ejercicio del derecho de desistimiento: Sin perjuicio de lo dispuesto en el artículo 105, el plazo de desistimiento concluirá a los 14 días naturales contados a partir de: a) En el caso de los contratos de servicios, el día de la celebración del contrato. b) En el caso de los contratos de venta, el día que el consumidor y usuario o un tercero por él indicado, distinto del transportista, adquiera la posesión material de los bienes solicitados, o bien: $1 .^{\circ}$ En caso de entrega de múltiples bienes encargados por el consumidor y usuario en el mismo pedido y entregados por separado, el día que éste o un tercero por él indicado, distinto del transportista, adquiera la posesión material del último de los bienes. $2 .^{\circ}$ En caso de entrega de un bien compuesto por múltiples componentes o piezas, el día que el consumidor y usuario o un tercero por él indicado, distinto del transportista, adquiera la posesión material del último componente o pieza. 3. ${ }^{\circ}$ En caso de contratos para la entrega periódica de bienes durante un plazo determinado, el día que el consumidor y usuario o un tercero por él indicado, distinto del transportista, adquiera la posesión material del primero de esos bienes. c) En el caso de los contratos para el suministro de agua, gas o electricidad -cuando no estén envasados para la venta en un volumen delimitado o en cantidades determinadas-, o de calefacción mediante sistemas urbanos o de contenido digital que no se preste en un soporte material, el día en que se celebre el contrato.

27. Artículo 105. Omisión de información sobre el derecho de desistimiento: 1. Si el empresario no ha facilitado al consumidor y usuario la información sobre el derecho de desistimiento, tal como se establece en el artículo 97.1.i), el periodo de desistimiento finalizará doce meses después de la fecha de expiración del periodo de desistimiento inicial, determinada de conformidad con el artículo 104. 2. Si el empresario ha facilitado al consumidor y usuario la información contemplada en el apartado 1, en el plazo de doce meses a partir de la fecha contemplada en el artículo 104, el plazo de desistimiento expirará a los 14 días naturales de la fecha en que el consumidor y usuario reciba la información. 
de la LGDCU ${ }^{28}$. Esta información habrá de ofrecerla el empresario en la lengua utilizada en la propuesta de contratación, o bien en la lengua elegida en la contratación y al menos en castellano y debe hacerlo de forma acorde con las técnicas de comunicación a distancia utilizadas en términos claros y comprensibles, respetando los principios de buena fe y de protección de los incapaces para contratar. Si la información se facilita en soporte duradero debe ser legible ${ }^{29}$.

Además, en el contrato electrónico al ser un supuesto contrato a distancia, el empresario está obligado a facilitar al consumidor la confirmación del contrato en un soporte duradero tras la celebración del mismo, ello siempre que no lo hiciera en el momento anterior a la celebración la celebración del mismo, en esa confirmación debe figurar el derecho al ejercicio de desistimiento del consumidor así como los costes de devolución o de ejecución del servicio ${ }^{30}$. La confirmación del contrato debe ser ofrecida por el empresario en soporte duradero y en un plazo razonable si el consumidor ha dado su consentimiento expreso y de que conoce que pierde su derecho de desistimiento ${ }^{31}$, como recoge la letra $b$ del art. 98.7 y art. $99.2 L G D C U$.

Para el ejercicio del derecho de desistimiento no se requiere ninguna formalidad, es decir el consumidor puede ejercerlo por cualquier medio, puede así realizarlo a través del formulario que le ofrezca el empresario, puede ejercerlo utilizando el formulario que se recoge en el anexo $B$ de la $L D C U$ o bien por medio de una declaración inequívoca tal como predica el art. 106.1 de dicho texto legal. En cualquier caso y aunque no se requiere realizarlo de una manera concreta, sí es aconsejable, por razones de seguridad jurídica, que se realice por un medio que permita dejar constancia del mismo, ya que será el consumidor quien tenga la carga de probar el ejercicio de este derecho, como dispone el artículo 72 $L G D C U^{32}$.

28. Artículo 97.1: i) Cuando exista un derecho de desistimiento, las condiciones, el plazo y los procedimientos para ejercer ese derecho, así como el modelo de formulario de desistimiento. j) Cuando proceda, la indicación de que el consumidor y usuario tendrá que asumir el coste de la devolución de los bienes en caso de desistimiento y, para los contratos a distancia, cuando los bienes, por su naturaleza, no puedan devolverse normalmente por correo, el coste de la devolución de los mismos.

29. Artículo 98 LGDCU.

30. Artículo 98.4 LGDCU: Si el contrato se celebra a través de una técnica de comunicación a distancia en la que el espacio o el tiempo para facilitar la información son limitados, el empresario facilitará en ese soporte específico, antes de la celebración de dicho contrato, como mínimo la información precontractual sobre las características principales de los bienes o servicios, la identidad del empresario, el precio total, el derecho de desistimiento, la duración del contrato y, en el caso de contratos de duración indefinida, las condiciones de resolución, tal como se refiere en el artículo 97.1. a), b), e), i) y p). El empresario deberá facilitar al consumidor y usuario las demás informaciones que figuran en el artículo 97 de una manera apropiada con arreglo al apartado 1.

31. Artículo 98.7 b) y art. 99.2 LGDCU.

32. Artículo 72: Prueba del ejercicio del derecho de desistimiento. Corresponde al consumidor y usuario probar que ha ejercitado su derecho de desistimiento conforme a lo dispuesto en este capítulo. 
Finalmente indicar que se trata de un derecho de carácter recepticio por lo que es necesario que el desistimiento sea comunicado al empresario, para que este derecho despliegue sus efectos ${ }^{33}$.

\section{Efectos del ejercicio del derecho de desistimiento}

La $L G D C U$ establece en su artículo 107 cuáles son los efectos que produce el desistimiento en los contratos a distancia.

En cuanto al empresario, el efecto principal que produce el desistimiento del consumidor, es la obligación de reembolsar al consumidor todos los pagos que éste haya efectuado. De igual manera deberá el empresario reembolsar al consumidor los gastos generados por la entrega, si bien este reembolso únicamente va referido a los gastos de entrega ordinarios, no a aquellos gastos de entrega urgentes o extraordinarios, que serán asumidos por el consumidor, tal y como se estipula en la Directiva 83/2011 sobre los derechos de los consumidores ${ }^{34}$.

El reembolso del empresario ha de efectuarse en el plazo de 14 días desde que el consumidor le informó de su desistimiento del contrato, si bien el empresario tiene la facultad de retener el importe del reembolso en aquellos casos en que el consumidor deba restituirle el bien o producto objeto del contrato, bien hasta el momento en que el empresario lo reciba, bien hasta el momento en que el consumidor le acredite que ya le ha efectuado el envío ${ }^{35}$.

En cuanto al consumidor, su desistimiento contractual le obliga a devolver al empresario el bien o producto adquirido. Esa devolución debe realizarla también en el plazo de 14 días $^{36}$ desde que comunicó su desistimiento al empresario y podrá hacerse por cualquier medio, si bien de nuevo se insiste que se realice por un medio que deje constancia de su realización.

\footnotetext{
33. Artículo 68 LGDCU.

34. Artículo 13.2 de la Directiva 83/2011: Obligaciones del comerciante en caso de desistimiento. 2. No obstante lo dispuesto en el apartado 1, en caso de que el consumidor haya seleccionado expresamente una modalidad de entrega diferente a la modalidad menos costosa de entrega ordinaria, el comerciante no estará obligado a reembolsar los costes adicionales que de ello se deriven.

35. Artículo 107 LGDCU: Obligaciones y derechos del empresario en caso de desistimiento: 3. Salvo en caso de que el empresario se haya ofrecido a recoger él mismo los bienes, en los contratos de venta, el empresario podrá retener el reembolso hasta haber recibido los bienes, o hasta que el consumidor y usuario haya presentado una prueba de la devolución de los bienes, según qué condición se cumpla primero.

36. Artículo 108 LGDCU: Obligaciones y responsabilidad del consumidor y usuario en caso de desistimiento: 1 . Salvo si el propio empresario se ofrece a recoger los bienes, el consumidor y usuario deberá devolverlos o entregarlos al empresario, o a una persona autorizada por el empresario a recibirlos, sin ninguna demora indebida y, en cualquier caso, a más tardar en el plazo de 14 días naturales a partir de la fecha en que comunique su decisión de desistimiento del contrato al empresario, de conformidad con el artículo 106. Se considerará cumplido el plazo si el consumidor y usuario efectúa la devolución de los bienes antes de que haya concluido el plazo de 14 días naturales.
} 
En determinados casos no será necesario realizar dicha devolución, pues es el empresario quien se ofrece a recoger el bien o producto.

Pero ¿quién asume los gastos de la devolución? Para responder a esta pregunta es necesario saber si el empresario informó convenientemente de dichos gastos al consumidor. De haberse informado al consumidor de dichos gastos, será éste quien deba asumir los mismos, en caso contrario será el empresario quien asumirá los costes de la devolución. ${ }^{37}$

\section{E. Excepciones}

Finalmente indicar que igual que la ley reconoce el derecho de desistimiento como una facultad del consumidor, también establece una serie de supuestos en los que el consumidor no tendrá reconocido este derecho, son los siguientes ${ }^{38}$ :

a) Suministro de bienes o prestación de servicios cuyo precio dependa de fluctuaciones del mercado financiero que la persona empresaria no pueda controlar y que puedan producirse durante el periodo de desistimiento.

b) Suministro de bienes confeccionados conforme a las especificaciones de la persona consumidora o claramente personalizados.

c) Suministro de bienes que puedan deteriorarse o caducar con rapidez.

d) Suministro de bienes precintados que no sean aptos para ser devueltos por razones de protección de la salud o de higiene y que hayan sido desprecintados tras la entrega.

f) Suministro de bienes que después de su entrega y teniendo en cuenta su naturaleza se hayan mezclado de forma indisociable con otros bienes.

g) Suministro de bebidas alcohólicas cuyo precio haya sido acordado en el momento de celebrar el contrato de venta y que no puedan ser entregadas antes de 30 días, y cuyo valor real dependa de fluctuaciones del mercado que la persona empresaria no pueda controlar.

h) Contratos en los que la persona consumidora haya solicitado específicamente al empresario que le visite para efectuar operaciones de reparación o mantenimiento urgente; si, en esa visita, el empresario presta servicios adicionales a los solicitados específicamente por el consumidor o suministra bienes

37. Artículo 108.1.II y III LDCU: II. El consumidor y usuario sólo soportará los costes directos de devolución de los bienes, salvo si el empresario ha aceptado asumirlos o no le ha informado de que le corresponde asumir esos costes. III. En el caso de contratos celebrados fuera del establecimiento en los que los bienes se hayan entregado ya en el domicilio del consumidor y usuario en el momento de celebrarse el contrato, el empresario recogerá a su propio cargo los bienes cuando, por la naturaleza de los mismos, no puedan devolverse por correo.

38. Artículo 103 del Real Decreto Legislativo 1/2007 de 16 de enero. 
distintos de las piezas de recambio utilizadas necesariamente para efectuar las operaciones de mantenimiento o reparación, el derecho de desistimiento debe aplicarse a dichos servicios o bienes adicionales.

i) Suministro de grabaciones sonoras o de vídeo precintados o de programas informáticos precintados que hayan sido desprecintados por la persona consumidora después de la entrega.

j) Suministro de prensa diaria, publicaciones periódicas o revistas, con la excepción de los contratos de suscripción para el suministro de tales publicaciones.

k) Contratos celebrados mediante subastas públicas.

1) Suministro de servicios de alojamiento para fines distintos del de servir de vivienda, transporte de bienes, alquiler de vehículos, comida o servicios relacionados con actividades de esparcimiento, si los contratos prevén una fecha o un periodo de ejecución específicos.

m) Suministro de contenido digital que no se preste en un soporte material cuando la ejecución haya comenzado con el previo consentimiento expreso de la persona consumidora con el conocimiento por su parte de que en consecuencia pierde su derecho de desistimiento.

\section{CONCLUSIONES}

En los últimos años estamos viendo como las compras a través de medios electrónicos son cada vez más frecuentes, convirtiéndose hoy día, en el ámbito del consumidor, en la forma más habitual de comprar.

Ese auge de la contratación electrónica se refleja también en su regulación, coexistiendo la normativa europea con la legislación española y la del resto de países que insisten a toda costa en garantizar los derechos de los consumidores que emplean medios electrónicos para realizar sus compras,

En el presente artículo se hace mención la legislación aplicable a este tipo de contratación así como los derechos que amparan al consumidor deteniéndonos de manera especial, por su importancia, en el derecho de información y el derecho de desistimiento del consumidor.

En general en las relaciones de consumo, el consumidor siempre es la parte débil del contrato, frente a la posición dominante que ostenta el empresario. Esta situación de desigualdad se hace aún más evidente dentro de la contratación electrónica, dado que no hay un contacto físico-personal entre los sujetos que contratan, quedando más expuesto el consumidor si cabe, a las exigencias y requisitos que impone el empresario, es en ese marco en el que el derecho de información que asiste al consumidor cobra una mayor importancia.

Pero ese deber que ha de cumplir el empresario no siempre se cumple, a veces la información aparece oculta, otras veces sesgada, y en ocasiones no es real. Es preciso que toda la información llegue al consumidor, solo así podremos decir que el contrato se ha celebrado con todas las garantías exigibles. 
Por su parte el derecho de desistimiento es un derecho que asiste a todo consumidor y en la contratación electrónica no es diferente, siendo un derecho reconocido y regulado por la normativa europea y española, que establecen no solo su forma de ejercicio sino también las consecuencias o efectos que produce el mismo.

Para concluir, cabe poner de manifiesto que pese a toda la protección que las distintas legislaciones ofrecen al consumidor, aún hay camino que recorrer con el fin de dotar de mayores y mejores garantías a la contratación electrónica eliminando así el temor a ser engañados cuando se contrata por medios electrónicos.

\section{REFERENCIAS}

- Acedo Penco, Ángel. Derecho de consumo: análisis jurídico-privado de la Ley General para la Defensa de los Consumidores de 2007, Madrid: Dykinson, 2012.

- Acedo Penco, Ángel. "Fundamentos constitucionales de la protección jurídica de los consumidores en el ordenamiento español y en la Unión Europea”, Ius: revista del Instituto de Ciencias Jurídicas de Puebla, 29 (2012): 7-29.

- Beluche Rincón, Ignacio. El derecho de desistimiento del consumidor, (Valencia: Tirant lo Blanch, 2009).

- Bercovitz Rodríguez-Cano Rodrigo. Tratados de contratos. Tomo II, (Valencia: Tirant Lo Blanch, 2013).

- $\quad$ Flass, Ghunter."El concepto de consumidor", Anuario de Derecho Civil, 12 (2017): 1-63. https://doi.org/10.22529/adc.2017(12)01.

- Marín López, Manuel Jesús. "El "nuevo" concepto de consumidor y empresario tras la Ley 3/2014, de reforma del TRLGDCU”, Revista CESCO de Derecho de Consumo, 9 (2014): 9-16. http://www.revista.uclm.es/index.php/cesco

- Mateu de Ros, Rafael. "El consentimiento y el proceso de contratación electrónica”, en Derecho de Internet, contratación electrónica y firma digital, ed. Por Rafael Mateu de Ros y Juan Manuel Cendoya Mendez de Vigo (Pamplona, Aranzadi, 2000): 29-84.

- Platero Alcón, Alejandro y Jiménez Asensio, Cristina. "El consumidor online en el ordenamiento jurídico español”, Revista Nuevo Derecho, 21 (2017): 57-80. 
- Picatoste Bobillo, Juan. "El derecho de información en la contratación con consumidores", Actualidad Civil, 4 (2011): 1-15.

- Tambussi, Carlos Eduardo. "Decisiones judiciales referidas al comercio electrónico en la Argentina desde el derecho de consumidores y usuarios", en Lex Revista de la Facultad de Derecho y Ciencia Politica de la Universidad Alas Peruanas, 16, 22 (2018): 101-130. http://dx.doi.org/10.21503/lex.v16i22.1651

RECIBIDO: 14/04/2021

APROBADO: 10/06/2021 